\title{
Learning from the Periphery in a Collaborative Robotics Workshop for Girls
}

\author{
Florence R. Sullivan, ${ }^{1, *}$, Kevin Keith ${ }^{2}$, Nicholas C. Wilson ${ }^{3}$ \\ ${ }^{1}$ College of Education, University of Massachusetts, United States \\ ${ }^{2}$ Department of Mathematics \& Computer Science, Landmark College, United States \\ ${ }^{3}$ Office of the Vice Provost for Teaching and Learning, Stanford University, United States
}

Copyright $\odot 2016$ by authors, all rights reserved. Authors agree that this article remains permanently open access under the terms of the Creative Commons Attribution License 4.0 International License

\begin{abstract}
This study investigates how students who are peripherally positioned in computer science-based, collaborative group work meaningfully engage with the group activity in order to learn. Our research took place in the context of a one-day, all-girl robotics workshop, in which the participants were learning to program robotic devices. A total of 17 girls, ages $8-13(\mathrm{M}=11.725)$ participated in the workshop. Participants were recruited from local middle schools, through the technology teacher. Data collection consisted of video and audiotaping all group interactions over the daylong workshop. The group discussions were then fully transcribed. In this study, we focus on two students from different groups who had less direct contact with the materials, and were thus positioned peripherally. We used microgenetic learning analytic techniques to analyze discourse patterns in order to characterize the engagement of both the two groups of which the students were a part, as well as the two students themselves. One of the groups demonstrated stronger coordination from a discourse perspective and the focal student in that group exhibited meaningful engagement, while the other group demonstrated weaker coordination from a discourse perspective and the focal student exhibited marginal engagement. This contrast allows us to begin to build a picture of the factors that support learning from the periphery. Our results indicate that agency exhibited in well-coordinated group discussions is a key aspect of meaningful engagement.
\end{abstract}

Keywords Robotics, Girls, Collaboration, Participation, Discourse Analysis

\section{Introduction}

The purpose of this paper is to report on our research related to students' collaborative learning during an all-girls, day-long robotics workshop. The question guiding this research is: How do students who are peripherally positioned in group work meaningfully engage with the activity in order to learn? This work builds on our previous research about group role negotiations and students' opportunities to learn in a robotics environment [1]. In that work, we found that students developed creative ways to actively negotiate who would control the robotics materials. We postulated that in a robotics context, learning is mediated most directly by interaction with the materials, hence the students ongoing negotiations over them. An observation from the previous study was that one individual persistently occupied a peripheral position in the group's work. This student was a girl who strongly identified with feminine roles (for example, Mother). We argued that the inherent gender inequality of society, and the identification of technology as a "male" activity [2-4], were social factors that served to peripherally position this feminine student. Indeed, canonical research on the role of gender status in collaborative group learning supports this interpretation [5].

In this study, we sought to create a seemingly more equitable learning environment by eliminating gender as a variable. However, in the all-girls robotics environment, we observed the same phenomenon of peripheral and central participation as marked by control of the robotics materials. And we observed group negotiations over who would control materials at any given time. Moreover, in our initial investigation into the formation of these roles, we have observed that some students appear to be able to assert an agentic identity from the periphery, while other students struggle to participate. In this study, we explore participation from the periphery of small group work in a robotics environment. The goal of this research is to develop greater understanding of how students learn from the periphery in order to guide instruction and curriculum development in technology rich environments, such as robotics.

Before moving on to our review of the relevant literature, we would like to address our work in relationship to Lave and Wenger's [6] notion of legitimate peripheral participation. While our work is certainly inspired by their work, it is different in a very important way. In our group 
interactions, there is no master. None of the girls involved in the two collaborative groups, analyzed here, had prior experience with robotics; none had mastered either building with Legos or writing computer programs. In this respect, central and peripheral participation does not refer to the level of knowledge or experience possessed by group members. Rather, it refers specifically to control of the technological devices, possession of which allowed the girls to engage centrally in the practices of either building the robotic device, or programming the robotic device. Here the girls are not apprenticed into the use of the tools, but given direct access to them for the purposes of learning. However, we did observe central and peripheral participation patterns arise. We seek to understand how students learn from the periphery even when the ones at the center of the activity are not masters of the activity.

\subsection{Learning and Engagement in Small Groups}

The literature on small group collaboration suggests that in problem solving contexts, groups must attend to aspects of both content and interpersonal relations [7]. Accordingly, groups' abilities to coordinate their interactions around these two spaces involves a range of cognitive and social tasks, which may impact the success of the groups' learning outcomes, and the opportunities of individuals within the group to participate in the problem solving process [8]. Barron [8, 7] and Mercer [9] for instance, argued that the qualities of groups' interactional exchanges, or "talk," may permit different modes of knowledge construction. Disputational talk, for example, may be characterized by disagreement and individualized decision making. Such exchanges are indicative of low coordination among a given small group. Conversely, exploratory talk, which involves constructive and critical engagement with each other's ideas, is a mark of highly coordinated problem solving. For this reason, not only are the qualities of a small group's "talk" indicative of its level of coordination, but also of how group members' opportunities to participate are created and shared.

At a macro level, engagement has been defined as when something catches the attention of a learner $[10,11]$. Through the sociocultural lens, a more micro level definition focuses on the social interactions that occur as a marker of engagement. Vygotsky [12] situates learning as a social process where the genesis of higher order thinking occurs through social interaction and, especially, language. An individual's learning evolves through the social negotiation of roles and the sharing of individual and collective knowledge that meditate the activity [13]. In this way, in a collaborative learning situation all of the participants are, theoretically, afforded an opportunity to contribute to the building of knowledge.

Engagement has also been characterized as meaningful changes in participation. Ryu and Lombardi [14] posit that in a science learning environment, engaging in discourse is fundamental to a process of change in epistemic identity (how students find a place of belonging in the environment) and epistemic agency (the practices associated with knowledge construction). Moreover, changes in discourse, such as discussion and argumentation, are indicative of changes in engagement [15]. In our own work, we have found that in order to position themselves more centrally in the activity of the group, students may discursively pivot towards a competent identity [1]. Such an identity pivot may be accomplished in a number of ways, for example, through a simple declaration "I'm good at building," to more indirect, playful approaches, "you build step one and two, I'll build step three, four, five and six, and seven, and eight and nine!" Students may also take the tack of asserting prior knowledge "I know how to do this," or seek to create an identity-based connection with the activity "let's make this [little LEGO figure] a girl!" We found that such identity pivots were aimed at creating space for participation that would, in turn, create space for learning and further development of an epistemic identity.

From a sociocultural lens, then, discourse patterns in the learning environment are indicative of collective and individual engagement and learning. Our research proceeds from the sociocultural position - we focus on both the groups discourse patterns and the peripherally positioned participants' discourse patterns to examine if and how they are meaningfully engaged in the activity.

\section{Materials and Methods}

This educational research project took place at a one-day, all girls introduction to robotics event. The event called "Girls Connect" is periodically offered to middle school aged girls in the Western Massachusetts region. The event is designed to introduce girls to the First Lego League (FLL) in order to stimulate their interest in FLL and robotics. The workshop is sponsored by the Commonwealth Alliance for Information Technology (CAITE). CAITE is a Massachusetts statewide initiative whose aim is to broaden participation in computing. The CAITE project originated through funds from the National Science Foundation. The Girls Connect event was held on a Saturday in November of 2014. The event took place at the Massachusetts Green High Performance Computing Center. The workshop included solving robotics problems using the Lego ${ }^{\circledR}$ Mindstorms ${ }^{\circledR}$ robotics system (see [16] for a description of this kit) and the FIRST ${ }^{\circledR}$ Lego ${ }^{\circledR}$ League challenge arena from 2011, Food Factor.

\subsection{Research Design and Participants}

The participants in this study included 17 girls, ages 8-13 $(\mathrm{M}=11.725)$ who attended 5 different schools in New England. Purposeful sampling was used to select students from various backgrounds and geographic areas from the pool of students who volunteered for the event. Four of the five schools were not meeting state standards for performance. One of the schools had a student population 
that was identified as $93.2 \%$ Hispanic. All of the participants were working with robotics for the first time.

The students were divided into six teams (five teams of 3 and one team of 2); girls from the same schools were on the same team. Chaperones/teachers accompanied each of the groups and were present for the entire day. Each of the six teams were given color coded t-shirts to wear for the day. For example, one team wore green t-shirts, one yellow, etc. The t-shirts bore the Girls Connect logo and were presented both as commemorative gifts to participating girls and chaperones, and also to function as an aid to the researchers in keeping track of who was on which team as the girls roamed about the room.

We focus on two participants from two different groups, each of whom was positioned on the periphery of the activity. In order to identify students who were positioned on the periphery, we viewed the videotapes and reviewed the transcripts. Our criteria for peripherality was twofold: first, if a student was neither the main programmer nor the main builder, she was positioned outside; second, if this outside person's ideas were not taken up by the group, she was peripherally positioned. We selected two cases where both of these conditions were met (Kelly and Kristina). Moreover, we selected one case that indicated meaningful engagement from the periphery and one case that indicated marginal engagement. This contrast allows us to begin to build a picture of the factors that support learning from the periphery. Pseudonyms are used throughout.

\subsection{Data Collection Methods}

We collected audio and video data at the one-day event from each of the girls and groups in the study. Each group of girls had their own worktable, a LEGO Mindstorms EV3 robotic construction kit, and laptop computer to build and program their robot. Two challenge arenas were set up in the room so that the girls could test their solutions (Figure 1). A video camera mounted on a tripod was used at each group table to capture the building and programming of the robots. Two additional cameras were used, one at each of the arenas, to capture the test-runs of the robots. See Figure 2 for an illustration of the room set-up. We chose to leave the cameras stationary so as to attenuate the impact of the cameras on the participants' activity.

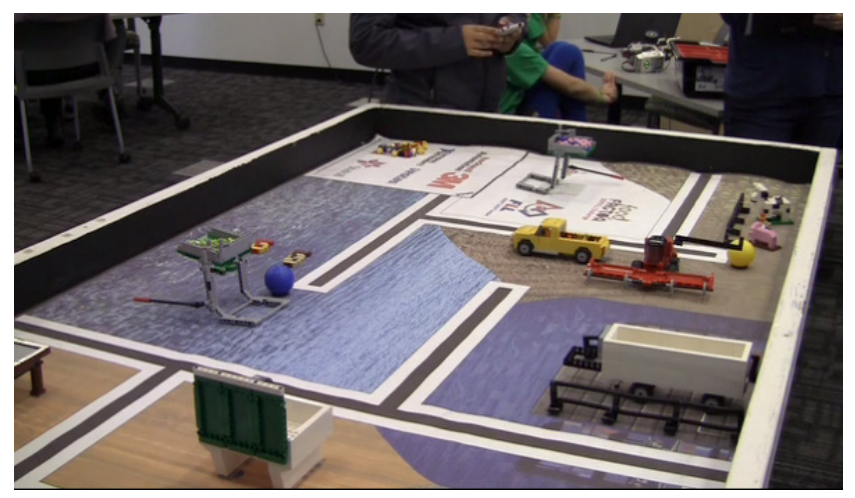

Figure 1. The Food Factor Arena

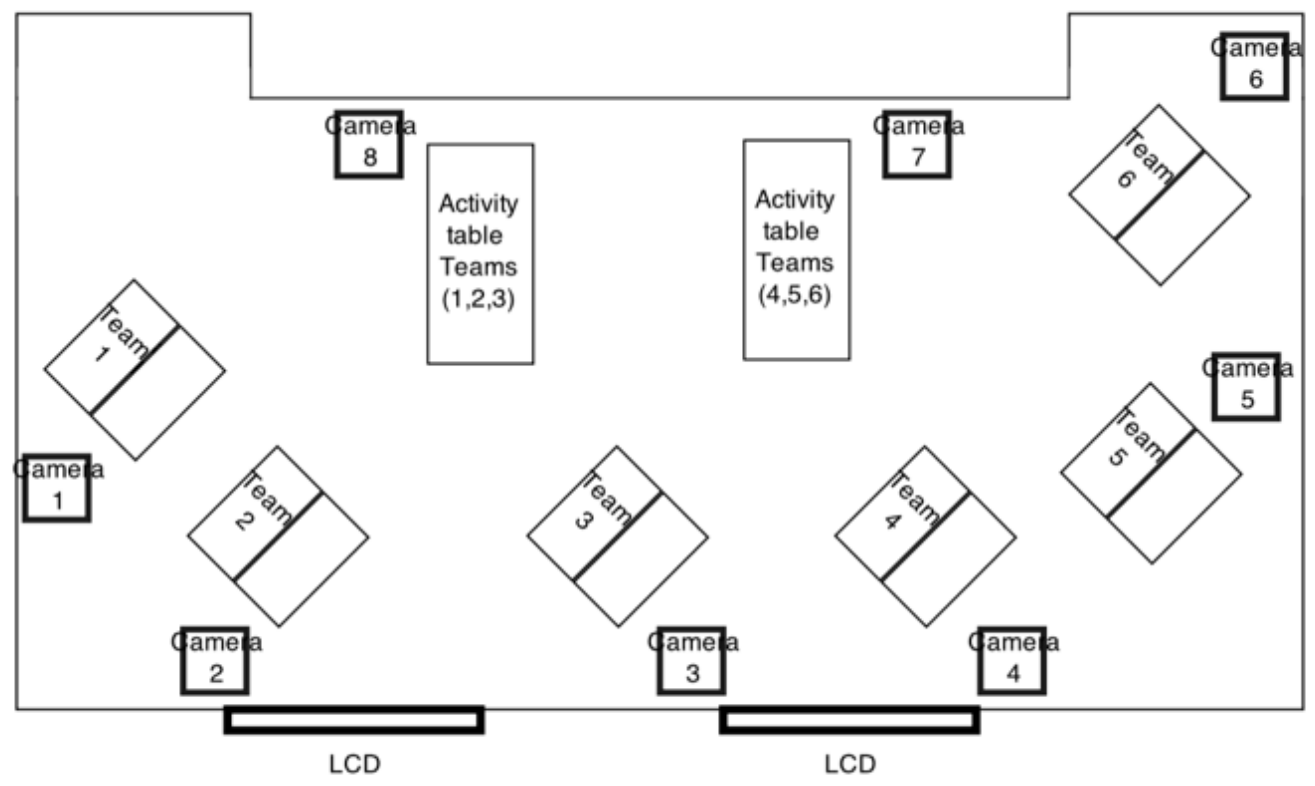

Figure 2. Research Video Camera Set-up 
Each of the participants in the study wore a wireless microphone; two of the Girls Connect presenters also wore a microphone. From these data, we created a video and audio recording of each group's activity and discussion for the day. A professional transcriptionist transcribed all group talk.

\subsection{Data Analysis}

In our previous work, we developed a troubleshooting qualitative model of student activity, focused on the troubleshooting cycle in the problem-solving environment [17] This troubleshooting cycle includes the following activity: "(1) writing and testing the program, (2) diagnosing problems with the program or structure of the device, (3) proposing and arguing for specific changes to the program/structure, (4) making changes to the program/structure, and (5) testing the device again" (p. 57). Based on our domain expertise and this troubleshooting cycle qualitative model of problem solving, we developed an analytic coding scheme (Table 1).

Table 1. Analytic Coding Scheme

\begin{tabular}{|c|c|c|}
\hline 1. Diagnosis & 2. Query & 3. Argumentation \\
\hline a. Evaluation & a. Clarification & $\begin{array}{c}\text { a. Group Regulation } \\
\text { (organization, mode, } \\
\text { negotiation, })\end{array}$ \\
\hline b. Confirmation & & $\begin{array}{c}\text { b. Content and Concepts } \\
\text { (building, programming - } \\
\text { comparing, explanation) }\end{array}$ \\
\hline c. Puzzlement & & c. Problem Definition \\
\hline d. Observation & & \\
\hline
\end{tabular}

In addition to these main codes, we also coded off-task talk (code \#4) and affirmations (code \#5). Application of our coding system was a deliberative process undertaken by the first and second authors of this paper. The process included viewing the videos and reading the utterances in context and discussing each one - in this way, we inductively coded the transcription. We then counted the instances of specific types of utterances. During the analysis of the utterances made by the participants, a difference in the quality of their comments became apparent. Therefore, we qualitatively analyzed the contributions that focused on problem solving (codes 1a $3 c)$.

Our further qualitative analysis of these utterances was guided by the criterion outlined in Table 2 . These categories are based on the work of Toulmin [18] and the subsequent refinement by Erduran, Osborne, \& Simon [19]. Toulmin defines argumentation as a set of claims, data, warrants, and backings that contribute to the content of the argument. Erduran et al. further categorized Toulmin's theory of argumentation into five levels of arguments to differentiate the quality of the discourse. The lowest level includes arguments that are purely a claim while higher levels of argument quality are typified by the addition of counter-claims and supporting data. However, these classifications were based on highly structured instruction in a science classroom, and the discourse was often teacher initiated and Socratic in method. In our research, the students' tasks were open-ended, and there was no scaffolding of the argumentation by the teacher. Therefore, we have adopted this modified set of codes to differentiate the quality of the discourse used in this environment.

Table 2. Discourse Quality Categorization

\begin{tabular}{|c|c|c|}
\hline Quality & Code & Definition \\
\hline \multirow{2}{*}{ Low } & Comment & A general comment \\
\cline { 2 - 3 } & Guess & An unsupported choice \\
\hline \multirow{2}{*}{ Mid } & Analysis & $\begin{array}{c}\text { Offering and understanding of the } \\
\text { issue }\end{array}$ \\
\cline { 2 - 3 } & Generalization & Restating previously stated ideas \\
\hline \multirow{3}{*}{ High } & Articulation & $\begin{array}{c}\text { Explaining difficult concepts (goes } \\
\text { beyond simple understanding) }\end{array}$ \\
\cline { 2 - 3 } & Alternative & Offering a substantively different idea \\
\cline { 2 - 3 } & Brainstorm & Introducing new ideas \\
\hline
\end{tabular}

We also examined two discourse trends (content-based and group regulation discussions) of the respective groups over the four-hour activity period. To do this we employed a methodology that we have been developing over the last two years. We term this methodology Microgenetic Learning Analytics (MLA) [20]. This method uses computational means for analyzing discourse interactions. We describe this method in the next section.

\subsection{Micro-genetic Learning Analytics}

Based on our troubleshooting cycle qualitative model of student activity, we sought to linguistically identify student activity over time. We accomplished this using a natural language processing library created by colleagues at Stanford University [21] featuring a parts-of-speech Treebank developed at the University of Pennsylvania [22]. Due to the relatively stable character of troubleshooting cycle activity, we postulated a relatively stable character to the domain of utterances that may be offered during these times: in short, an identifiable speech genre [23]. We reasoned that the parts-of-speech tagger would begin to help us identify types of utterances that may all be doing the same type of "work" in terms of the troubleshooting cycle; for example, we sought to linguistically identify periods of discourse devoted to engaging with the robotics content, and periods of discourse devoted to the regulation of the group. We selected this dichotomy based on Barron's $[8,7]$ notion of coordination as discussed above. We hypothesized that groups that are coordinating well with one another may be more content focused, and those that are not as well coordinated may spend more time on group regulation (who will do what). This seems especially true for group work where control of materials is a key aspect of learning.

\subsection{N-gram Analysis}

We chose to work with utterances at the level of the bigram (two words) and trigram (three words). We selected 
these n-grams because we reasoned these were the smallest level at which complete utterances might be made. To accomplish the discourse analysis, the transcripts of the words uttered by the students were broken down into tuple or duple (n-grams) word segments which were classified in such a way as to retain temporal differentiation. Single word utterances were not considered for this analysis. An utterance of two words was included in the analysis if and only if the entire utterance consisted of two words. Any utterance of three or more words was then divided into multiple overlapping three-word segments and included for analysis. For example, the sentence "but we need a ruler to make it go far away" would have been divided into 9 segments: but we need, we need a, need a ruler, a ruler to, ruler to make, to make it, make it go, it go far, go far away. The data set for this analysis included 6,662 utterances which produced 39,575 unique n-gram segments of text. There were slightly more trigrams produced by Kelly's group $(20,846)$ than Kristina's group $(18,729)$.

These trigram and bigram segments were then processed through the Java implemented Stanford log-linear parts-of-speech (POS) tagger [21]. POS taggers tokenize individual words and then utilize computational methods to assign a POS (such as noun, verb, conjunction, etc.) to each word. The Stanford POS tagger utilizes the Penn Treebank tag set [22].

Based on our prior work with parts of speech in the domain of troubleshooting cycles, the n-grams were programmatically linked with an analytic code (see Table 1). For example, the text segment "Now do the" has a POS tag of "RB VBP DT," which is an adverb, verb, and determiner. This n-gram, as well as all others with the same POS tag, was linked to the code Activity Negotiation. This list of links from the POS tag to the analytic coding scheme was created by the first and second authors through a deliberative process with a training dataset. Some n-grams were not coded beyond being assigned the POS tag string. This was the case if it was clear that the n-gram consisted of ideas belonging to two separate sentence clauses. Once the coding of the data sets was complete, 8,520 unique n-grams were linked to the analytic coding scheme.

The last step in this process was to group the coded n-grams into two categories. The n-grams that were coded with any of the Group Regulation or Affirmation codes were included in the Group Regulation category. All other coded n-grams were included in the Content category. In this way, we produced an analysis of the type of on-task discourse contribution made by each girl in each group. Our analysis has allowed us to develop an understanding of the differences in discourse activity at the group level, as well as at the individual level.

\section{Results}

\subsection{Group Discourse Trends}

We begin by presenting the results of each group's Content and Group Regulation MLA analysis. Our two focal groups consisted of three girls each. The line graph presented in Figure 3 represents the trends of discourse focused on robotics content over the four-hour period for the light blue t-shirt group, of which Kelly was a member. Frequency (y-axis) refers to the number of trigrams per $250 \mathrm{n}$-grams that received content related codes. For example, for the first 250 n-grams, about 70 of one of Kelly's group members' (Izzy on the chart) trigrams received a content code. While the $\mathrm{x}$-axis represents the number of n-grams spoken, it presents them chronologically. So left to right in these line graphs also represents time.

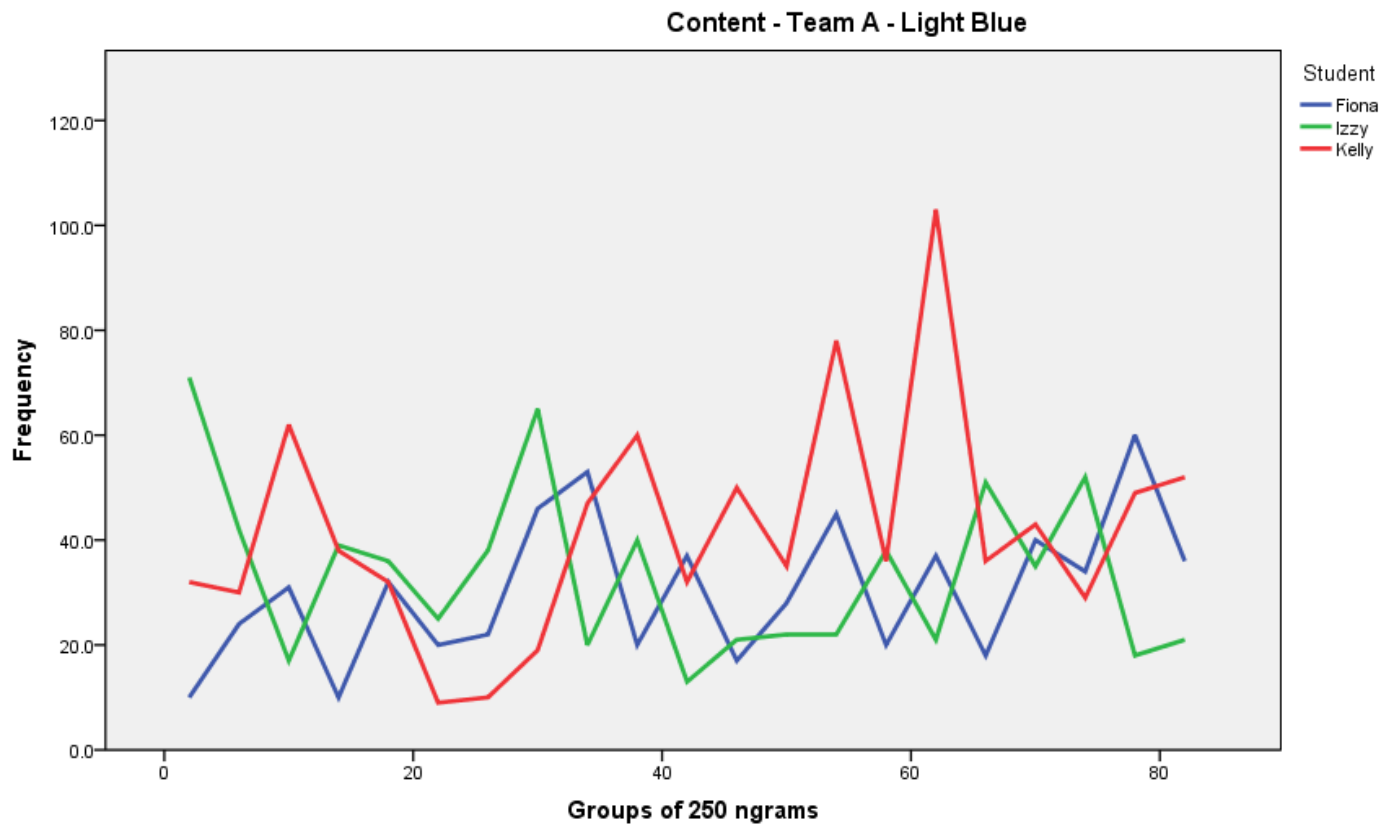

Figure 3. Content Discourse Light Blue Group 
As can be seen in Figure 3, Kelly is actively involved in the content discussion. In fact, at a later point during the day, she appears to make the largest contributions to the content discussion. Moreover, while it takes the light blue group a little time to get in synch, the group participants' comments appear to co-vary over time, as can be seen from the parallel movement of the peaks and valleys of the trend lines. The girls in this group appear to be engaged in conversation with one another about the content of their robotics activity over the four-hour period.

A similar trend of co-variation is observable for the light blue group in terms of their group regulation discussions (Figure 4). However, it is also clear that Kelly pays the most attention to group regulation. This may be due to the fact that she is peripherally positioned, and therefore, perhaps, most concerned with finding ways to be involved in what the group is doing. Having said that we did notice, however, that after the initial surge in group regulation talk, Kelly had two large peaks in content-related talk; perhaps the group regulation talk "worked" with regards to generating opportunities to be more centrally involved.

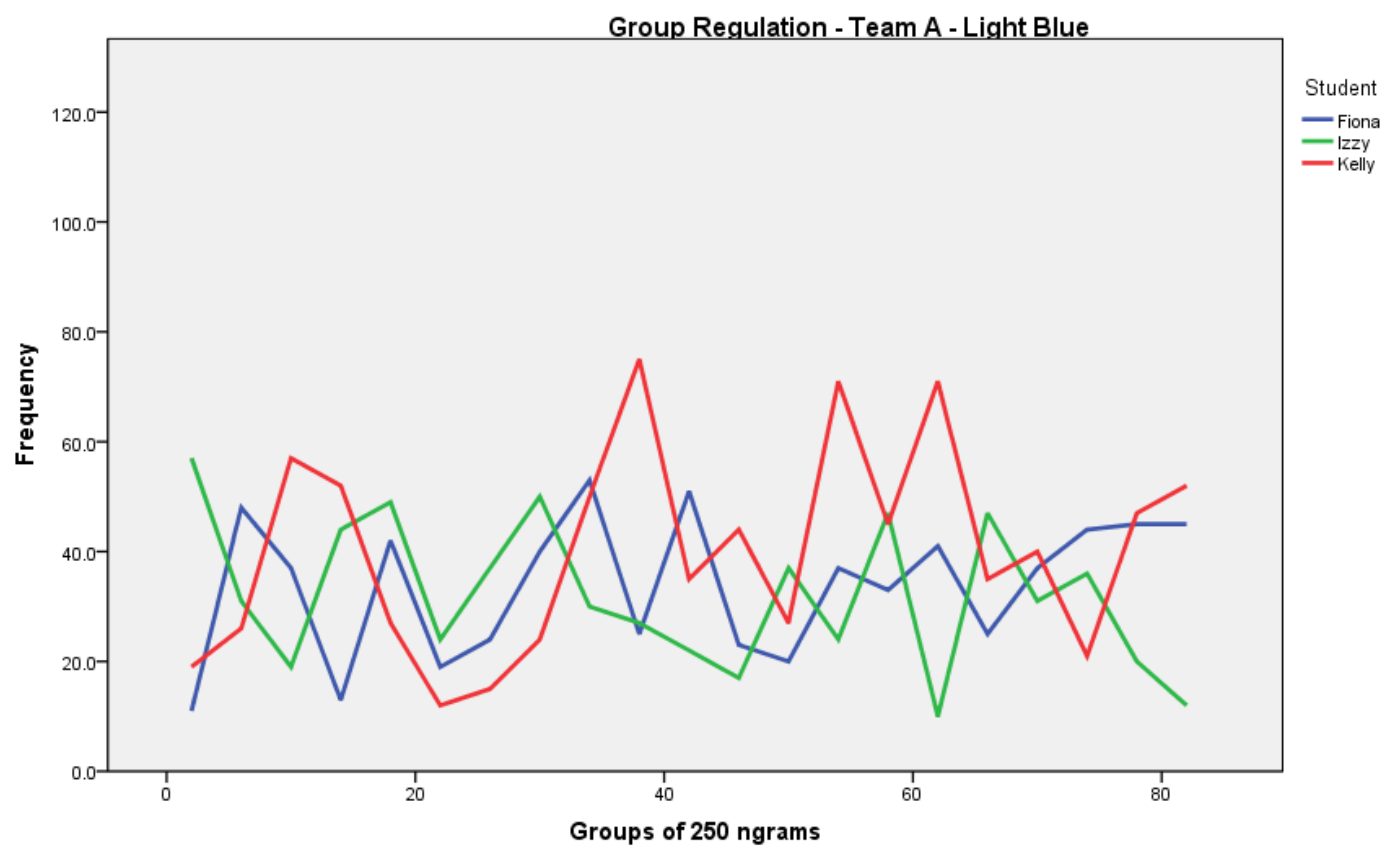

Figure 4. Group Regulation Discourse Light Blue Group

Figures 5 and 6 present the line graph discourse analyses for the light grey t-shirt group, of which Kristina was a member.

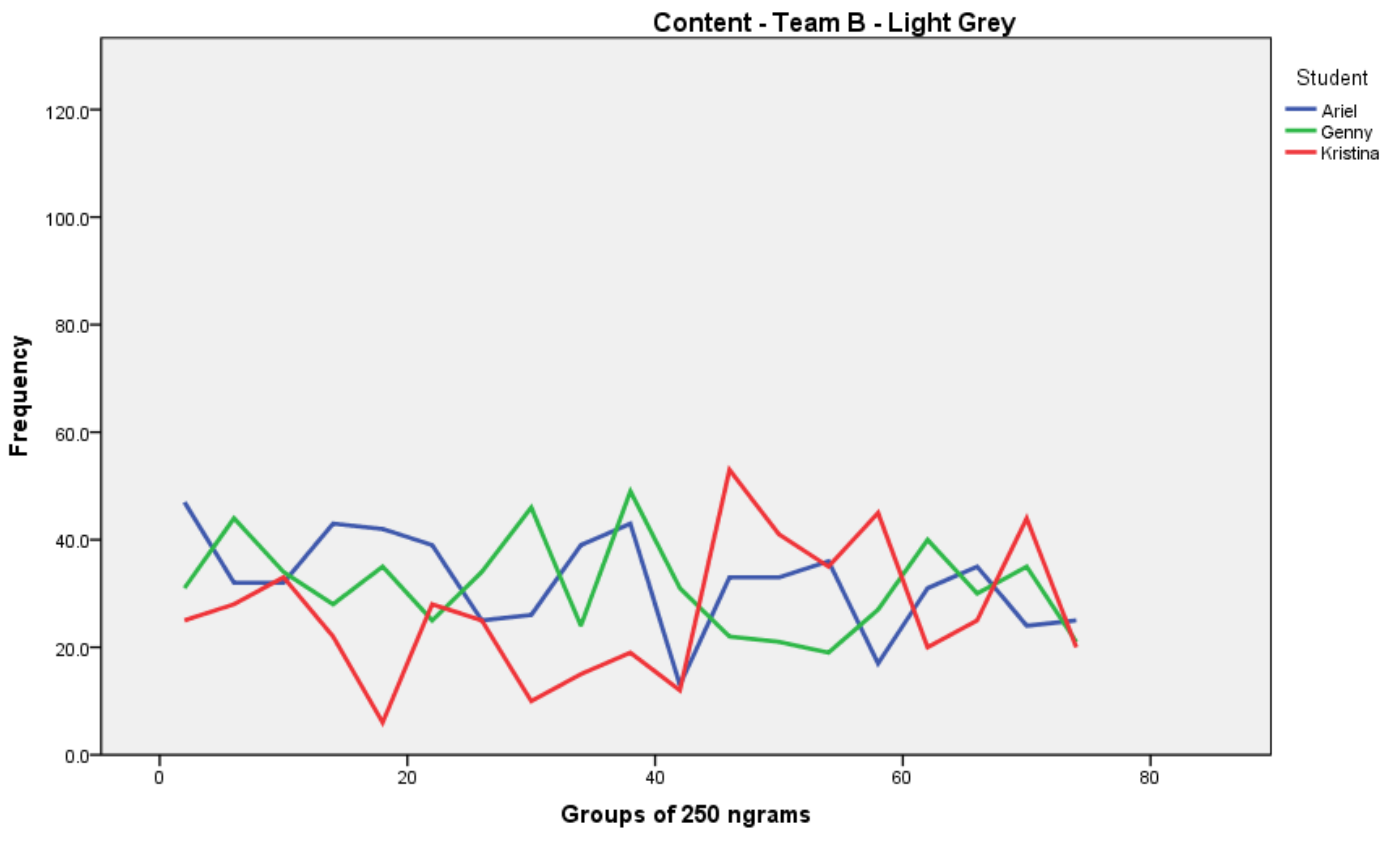

Figure 5. Content Discourse Light Grey Group 


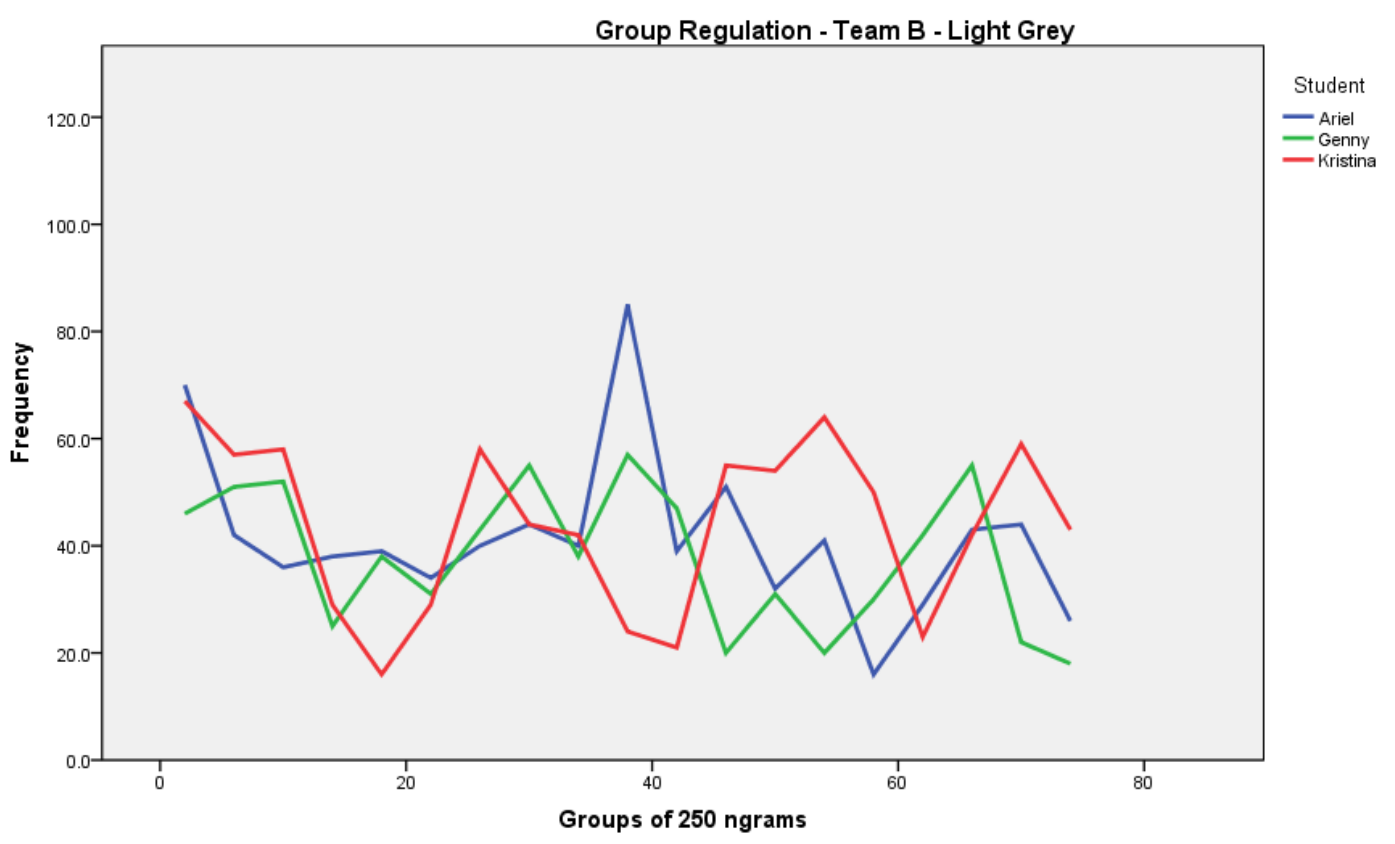

Figure 6. Group Regulation Discourse Light Grey Group

As can be seen in Figure 5, the light grey group trend lines feature a more disparate conversation in that the lines do not appear to peak and recede in parallel. Rather, it seems that each girl's comments related to content are spoken without much response from the other group members. In comparison to the light blue group, the light grey group's peaks are shorter and Kristina appears to make fewer content based contributions to the group during the first half of the day. She does appear to participate more towards the middle of the session and again at the end. But, it takes her quite awhile to become involved in the content-based discussion. Moreover, the entire group only begins to cohere towards the end of the day.

Similar to the content discussion results, Figure 6 shows that the group regulation discussion is less in synch for the light grey group than the light blue group. Also, it is clear that Kristina contributes more to the group regulation discussions than to the content discussions, with twice as many high peaks observable. While Kristina's group member, Ariel, also contributes a lot to the group regulation discussion, it is clear from the line graph that Kristina spends a lot of time during the second half of the working session attempting to negotiate the work of the group. Comparatively, this effort on Kristina's part is similar to the effort made by Kelly as regards group regulation. However, unlike Kelly, Kristina's group regulation contributions were not followed up by contributions to the content-based discussion. Moreover, from the analysis presented next, it is clear that Kristina also spends a lot of time engaged in off-task talk during the second half of the session (see Figure 8).

\subsection{Frequency of Types of Talk for Peripheral Participants}

To further analyze the discourse contributions of the peripheral participants, we present a quantitative analysis of their respective individual utterances over the course of the study. Figures 7 and 8 present the respective discourse profiles of Kelly and Kristina over a four-hour period using the analytic coding scheme derived from our troubleshooting cycle qualitative model of student activity. As can be seen, Kelly offers more comments focused on diagnosis $(1 \mathrm{a}-1 \mathrm{~d})$ and on building content and concepts (3b1c-3b2e) than Kristina. Moreover, Kristina spends more time discussing the organization of tasks and roles than does Kelly (3a3), and she spends much more time engaged in off task talk (4). The colored vertical lines indicate the number of each type of comment for each of the four active problem solving hours in the study. 


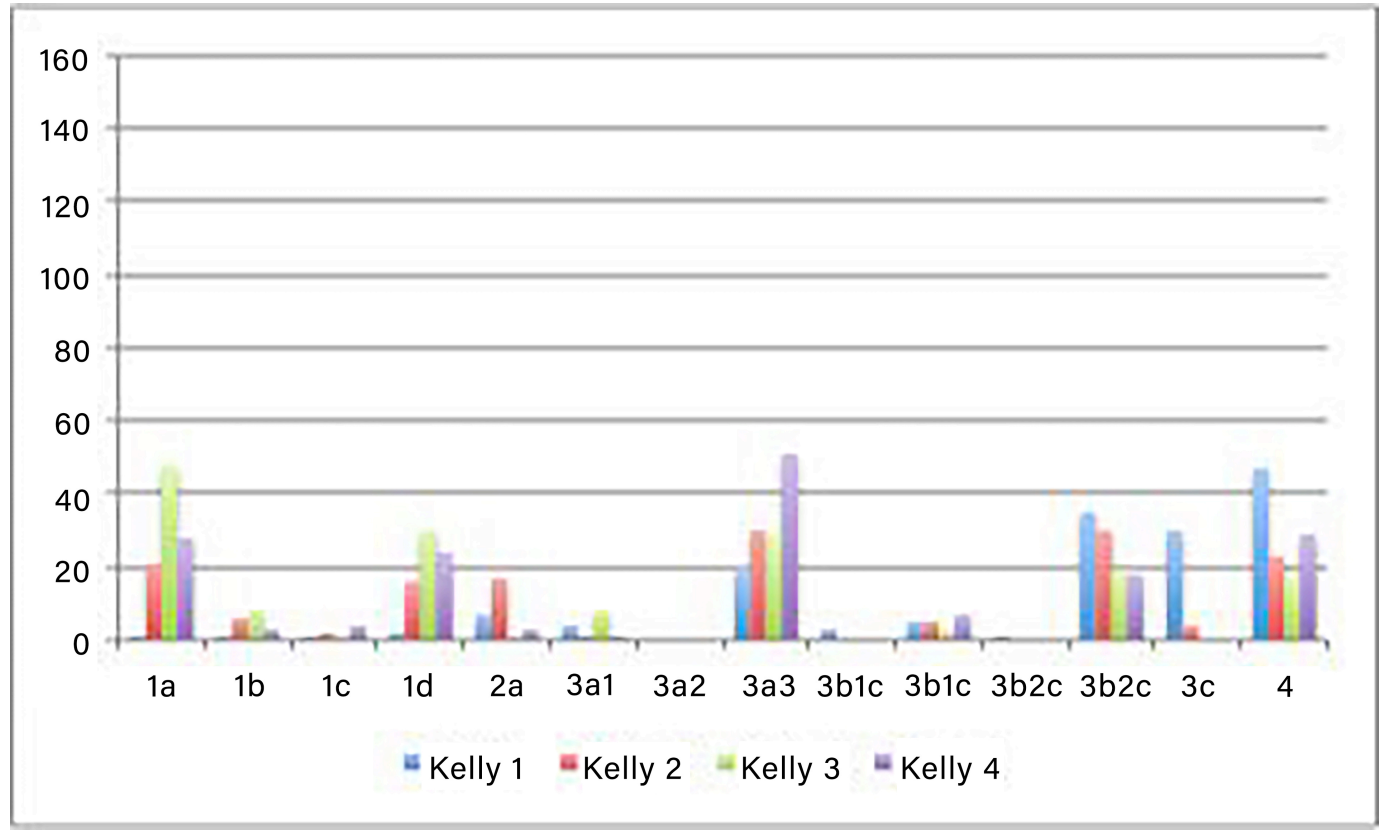

Figure 7. Kelly's Discourse Activities by Hour

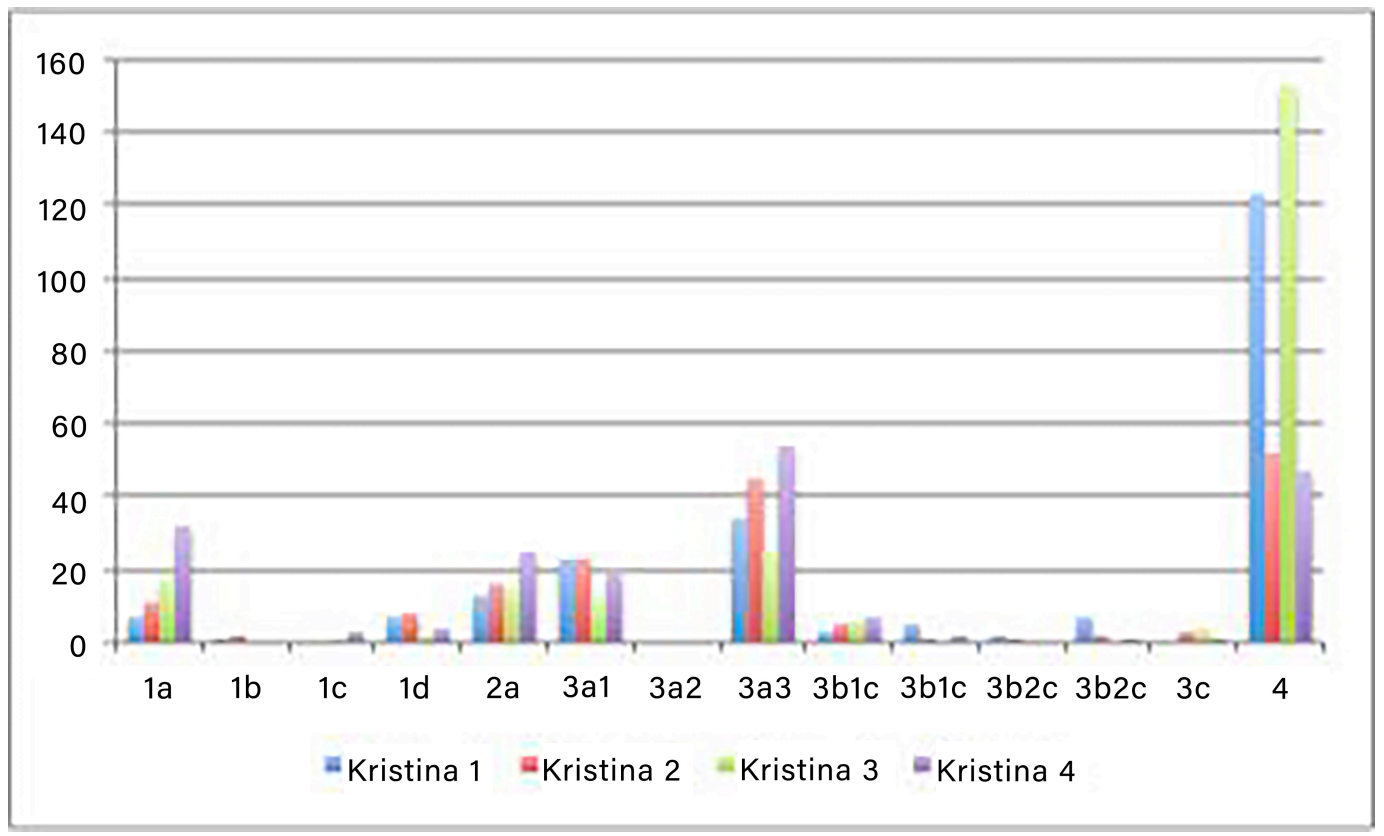

Figure 8. Kristina's Discourse Activities by Hour 


\subsection{Quality of Comments}

As argued above, engaging in the content discourse is most indicative of student learning [14]. Therefore, we now present a deeper qualitative analysis of the peripheral participants' content-based contributions to the discussion. As can be discerned from Figures 7 and 8, Kelly and Kristina made most of their contributions to the content discussion in the areas of diagnostic evaluation, diagnostic observation, and argumentation: content and concepts: building elements. This aspect of our data analysis helps to more clearly illustrate the nature of the discourse differences between Kelly and Kristina that may account for differences in learning from the periphery. As discussed in the methods section, our argument quality analysis is based on the work of Toulmin [18] and Erduran, et al., [19].

\subsection{Diagnostic Evaluation}

Table 3 represents diagnostic evaluation comments made by each participant during the study. The comments are presented chronologically; the first comment from Kelly was made between hours 3-4 of the study, the next comment between hours 4-5 and the last comment between hours 5-6. As noted earlier, the quality judgment helps to provide an important distinction as regards the level of discourse engaged in by the two girls and shows growth over time for both girls.

Table 3. Diagnostic Evaluation Utterances

\begin{tabular}{|c|c|c|}
\hline Participant & Utterance & Quality \\
\hline \multirow{3}{*}{ Kelly } & $\begin{array}{l}\text { And it then it got stuck on the } \\
\text { ball but it didn't go over the } \\
\text { ball. }\end{array}$ & Analysis (Mid) \\
\hline & $\begin{array}{l}\text { It's like yeah, yeah not the } \\
\text { balls but like the, cos they } \\
\text { have like, I don't know if } \\
\text { they'll like effect anything } \\
\text { like the width of them. }\end{array}$ & Brainstorm (High) \\
\hline & $\begin{array}{l}\text { It came over here it knocked } \\
\text { them out and it goes right } \\
\text { here, um it knocked the corn } \\
\text { out and it hit the ball off, but } \\
\text { then it backed up this way } \\
\text { and pushed the harvester all } \\
\text { the way over here. }\end{array}$ & Articulation (High) \\
\hline \multirow{3}{*}{ Kristina } & $\begin{array}{l}\text { Oh that's (the scrubber) } \\
\text { thing. }\end{array}$ & Comment (Low) \\
\hline & $\begin{array}{l}\text { Yeah we'll probably get one } \\
\text { (done) later. }\end{array}$ & Comment (Low) \\
\hline & $\begin{array}{l}\text { I didn't do anything it just } \\
\text { randomly }\end{array}$ & $\begin{array}{l}\text { Comment } \\
\text { (Low) }\end{array}$ \\
\hline
\end{tabular}

Most of this talk occurred at the arena after a test run of the robot for a challenge. Each of the participants showed growth in their utterances as the day progressed. However, more of Kelly's utterances tended toward direct analysis of the issue at hand, as evidenced by the indexical use of "it" to represent the robot. When Kelly is involved in evaluation, she often is speaking directly about the actions that the robot took in relation to the challenge and the arena. Kristina does use the word "it" on occasion, but often uses elliptical construction. For example, in the utterance, "Hmm, maybe we can focus on the angle a bit more," she could be talking about either the initial placement of the robot or the angle of the path that the robot was programmed to follow. Kristina does appear to be making connections, however her use of language to describe her understanding is not as specific as that used by Kelly.

\subsection{Diagnostic Observation}

Table 4 presents the diagnostic observations made by each of the focal participants over the same three-hour period.

Table 4. Diagnostic Observation Utterances

\begin{tabular}{|c|c|c|}
\hline Participant & Utterance & Quality \\
\hline \multirow{3}{*}{ Kelly } & $\begin{array}{c}\text { Okay, I think it needs a little bit } \\
\text { of help on the placement } \\
\text { sometimes, like }\end{array}$ & Analysis (Mid) \\
\hline & $\begin{array}{l}\text { Well I think that it goes } \\
\text { crooked, when it comes over } \\
\text { here it comes over, it turns but } \\
\text { then it ends up going crooked so } \\
\text { it just hits it like that. }\end{array}$ & Articulation (High) \\
\hline & $\begin{array}{l}\text { I, like I noticed when it was } \\
\text { coming back it backed up (?) } \\
\text { and backing up this way back to } \\
\text { base, it would have been easier } \\
\text { I think it's just easier. Okay. }\end{array}$ & $\begin{array}{c}\text { Analysis (Mid) } \\
\text { Alternative (High) }\end{array}$ \\
\hline \multirow{3}{*}{ Kristina } & It's kind of glitching. & Comment (Low) \\
\hline & $\begin{array}{l}\text { Hmm, maybe we can focus on } \\
\text { the angle a bit more. }\end{array}$ & $\begin{array}{l}\text { Generalization } \\
\text { (Mid) }\end{array}$ \\
\hline & $\begin{array}{l}\text { Uh so close, more force. I got } \\
\text { this, we need more speed. }\end{array}$ & $\begin{array}{l}\text { Analysis (Mid) } \\
\text { Brainstorming } \\
\text { (High) }\end{array}$ \\
\hline
\end{tabular}

Kelly's skills as an observer are apparent in these utterances. She is present for almost every test run of the robot at the arena and is obviously paying attention to what is going on. The robot moves fairly quickly, and a lot happens in the 5 to 10 seconds that the robot is running its program. Kelly often initiates an explanation about what transpired on the course. As the day progressed, these explanations were often initiated as a direct request from her teammates. She often not only explains what is happening, but offers additional data on how the program can be improved. While Kristina also participates in observing the test runs at the arena, she does not observe all of them. For example, she took two "coffee breaks" that the other students did not take. Also her utterances regarding observations are never specific and do not offer much in the discourse regarding the successful completion of the challenge.

\subsection{Argumentation: Content and Concepts}

The physical environment of the group table allowed all of the students access to the building elements. However, in both of our focal cases, because they were on the periphery of this activity, our participants did not initially have access to the object that was being built to help solve the challenge. 
Additional building elements, often a plough or a claw, were necessary to augment the robot's ability to complete the challenge. Kelly was often actively observing the building of these parts, as is evidenced by her discourse. She offered help and suggestions both at the group table as well as the arena. Near the end of the day she attempted to make a move toward improving the plough because she saw an issue with its design. Although Kristina had similar access to the materials and the building process as did Kelly, her utterances show that she took a much different role in this process. In hour 4 , she talks about adding an accessory to the robot that does not move the group forward toward solving the challenge. In hour 5 , we found no evidence that she offered any help toward the building elements. In hour 6 , she does offer some assistance, but because her experience with the pieces has been so minimal, she doesn't know the names of the pieces nor the implement that they have built. Table 5 presents a comparative analysis of representative comments uttered by each girl over three hours in the afternoon.

Table 5. Building Elements Explanation Utterances

\begin{tabular}{|c|c|c|}
\hline Participant & Utterance & Quality \\
\hline \multirow{7}{*}{ Kelly } & $\begin{array}{c}\text { So I'm thinking that we should } \\
\text { extend the plough with one of } \\
\text { those little five notch, things, it } \\
\text { will only, it will add on four } \\
\text { notches, if we add on this. }\end{array}$ & Articulation (High) \\
\cline { 2 - 3 } & $\begin{array}{c}\text { Okay, okay so...this part } \\
\text { before was still getting caught } \\
\text { on that so I'm gonna try and } \\
\text { perfect this by turning it to a } \\
\text { five notch instead of seven } \\
\text { notch. }\end{array}$ & Alternative (High) \\
\cline { 2 - 4 } & $\begin{array}{c}\text { Like I made a second plough, } \\
\text { because like I was thinking, I } \\
\text { was kind of thinking that that } \\
\text { one's kind of like, like it might } \\
\text { not work. Because like it just } \\
\text { doesn't seem like it's working } \\
\text { right now, so like. }\end{array}$ & Brainstorming \\
(High)
\end{tabular}

\section{Discussion}

The results of our analysis reveal two important trends that bear on the question of learning from the periphery in technology rich, small group collaborations. First, the coordination level of the group appears to have an impact on the ability of the peripheral student to learn. Second, the type and quality of an individual's verbal interactions with other group members appears to influence opportunities to learn in the group. We address each in turn.

Based on the MLA analysis of each group's content and group regulation discussions, it appears that Kelly's group achieved higher levels of coordination of group work. As can be seen in Figures three and four, there was a great deal of alignment of the peaks and valleys related to the discourse in Kelly's group. This alignment would seem to indicate that the girls were in synch with one another as they jointly discussed the content of the problem to be solved and/or jointly negotiated group activity. The coordination of group work, arguably, created an opportunity for Kelly to engage intellectually with the activity, even though she was not centrally involved with building the robot and programming it.

In contrast, Kristina's group's discourse activity (as represented in Figures 5 and 6) indicates that the group is less well aligned with one another. Both line graphs reveal a lack of co-variation in the peaks and valleys of both the content and the group regulation discussions; there is little parallel movement observable in this group's discussions. Since Kristina's group was not able to cohere as a group that worked well together (from a discourse perspective), Kristina's position on the periphery of the main activity became even more precarious; without a strong discussion within the group and lacking access to the learning materials, Kristina's opportunities to learn in the activity were substantially foreclosed.

As regards learning from the periphery, we note that the status of individual group members will affect their ability to meaningful participate in group activity and discussions [5]. Status differentials may be pre-existing or they may emerge as work in the group is undertaken. For example, members of the group may attempt to implement an identity pivot during the activity. As discussed above, identity pivots are typified by actions or discourse with an intent to change the status/role of the group member. However, in order for these identity pivots to be successful, an individual's utterances must be aligned with the social discourses of the group. Esmonde [24] has noted it is just such an alignment that helps to position a student for meaningful participation in group work, and influences the interaction of differently positioned students.

From the sociocultural viewpoint, it is the type and quality of Kelly's verbal contributions to the general problem solving activity that is indicative of both her engagement and her learning. Kelly, like Kristina, was positioned outside of the main group work of building and programming the robotic device, indicating lower status in the group. Yet, she stayed intellectually engaged in learning by carefully observing all of the activity of the group. She was clearly involved in every troubleshooting cycle. Her verbal contributions featured evaluation and observation of the robotic device during test runs. She also continued to make suggestions for structural changes to the robotic device and, over time, her contributions to programming increased, though she made fewer such remarks overall. Her comments 
were consistently of a higher level quality on our argumentation scale. In this way, it is possible to see that Kelly, though peripherally positioned, was still able to make sense of and learn in the activity. One option to explain this inclusion was that since her discourse was aligned with the social discourse of her group, she was able to affect her "access to valued forms of participation" [24]. Her epistemic identity in this group may be thought of as observer and evaluator. Kelly did not engage in any identity pivots, perhaps because she never saw herself as outside of the group's activity.

Kristina, on the other hand, was not involved in every troubleshooting cycle. She took "coffee" breaks during group learning time. She may have taken these breaks as a result of not having a central role in the activity. And, indeed, at times, she remarked on the fact that she did not feel like she was contributing to solving the problem. Moreover, Kristina did make discursive identity pivots but they were aimed at other people's competence, rather than her own, positioning herself as less able. For example, at one point, she says to one of her teammates "You are the master programmer..." Despite this positioning, Kristina's discourse patterns show that she continually sought to negotiate a meaningful role for herself with her teammates. It is perhaps this appeal to participation, as oppose to actively adopting an available role (for example, observer/evaluator) that contributed to Kristina's lack of meaningful engagement. In contrast, Kelly did not engage in this type of labor negotiation talk, but rather focused on the problem being solved and made meaningful contributions to group work. From Mercer's perspective, Kelly and her group were involved in both exploratory and cumulative modes of talk. In other words, their discussions were harmonious and also aimed at building the groups' knowledge. Meanwhile, Kristina's talk did not contribute to the groups' ability to explore the problem, or cumulatively develop a better understanding of the problem.

Another difference in Kristina and Kelly's discourse patterns is Kristina's use of humor. Kristina seemed to use humor as a means of engaging with the group and the activity. She named the robot, Eve, and decided that Eve was an evil robot, bent on destruction of the arena; this playful discourse was not picked up by her group members. In prior work, we have found that playful talk can serve an important function in group role negotiation and activity regulation, but only if it is an aspect of the groups' general discourse [1]. So, such a strategy for Kristina is not automatically unhelpful. However, in this particular case, since playful talk was not a general feature of this group's social discourse, Kristina was not able to gain traction with this strategy.

In fact, it may be true that as Kristina continually sought to re-negotiate the group's division of labor, her frequent breaks and her playful talk served to further marginalize her within her group. Whereas, Kelly's continual focus on the problem at hand and her increasingly sophisticated analysis of the problem allowed her to remain meaningfully engaged in the activity - her epistemic identity firmly developed from the periphery.

\section{Conclusions}

Our research contributes to the literature on collaboration in computer science learning contexts in a unique way. Rather than focus on the characteristics of well or ill-functioning groups $[8,7]$ the role of friendship $[25,26]$ the role of status $[5,24]$, or the quality of overall discourse [9], we focus on the participation of the learner who is positioned on the periphery of the group. Our analysis suggests that both well and ill coordinated groups may include a member who is positioned peripherally. In focusing on how students on the periphery find ways to become and stay meaningfully engaged in the activity, we aim to provide insight to practitioners related to supporting such activity. Group composition may well be the most important aspect of this puzzle. If Kristina had been in a group that was able to work together in a more coordinated fashion, it is likely that her opportunities to learn would have expanded, regardless of her ability to take control of either the building or programming activities. Teaching students how to engage in meaningful discussion while working collaboratively, teaching students how to manage and share the tasks at hand, teaching students how to make room for other's ideas are key activities for supporting collaborative group learning.

One concern that should be considered is the role of competition in creating poorly coordinated groups. The Girls Connect workshop follows the First LEGO League (FLL) model and is meant to serve as an introduction to the FLL. While the FLL seeks to downplay competition through a number of mechanisms, the Girls Connect workshop ended with a competition, and each of the teams were well aware that they were involved in this competition. While the competitive element is meant to increase students' motivation, it may motivate some children to become too dominating in the quest for victory. Serious consideration must be given to creating motivating cooperative activities for children to engage in while studying with computational media such as robotics. In truth, the technological working teams of tomorrow will need to rely a great deal on cooperation to move projects forward. Cooperative activities towards the resolution of a shared problem may be an important pedagogical element towards enabling well-coordinated collaborative learning groups.

\section{Acknowledgements}

The research reported in this paper was supported by a grant from the National Science Foundation (DRL-1252350). Any opinions, findings, and conclusions or recommendations expressed in this material are those of the author(s) and do not necessarily reflect the views of the NSF. 


\section{REFERENCES}

[1] Sullivan F.R. \& Wilson, N. (2015). Playful talk: Negotiating opportunities to learn in collaborative groups. Journal of the Learning Sciences, 24(1), 5-52. DOI: $10.1080 / 10508406.2013 .839945$

[2] American Association of University Women (2010). Why so few? Women in science technology engineering and mathematics. Washington, DC: Author.

[3] Margolis, J. (2008). Stuck in the shallow end: education, race and computing. Cambridge, MA: MIT Press.

[4] Nosek, B. A., Smyth, F. L., Sriram, N., Lindner, N. M., Devos, T., Ayala, A., \& Bar-Anan, Y. (2009). National differences in gender-science stereotypes predict national sex differences in science and math achievement. Proceedings of the National Academy of Science, 106(26), 10593-10597.

[5] Cohen, E.G. (1994). Restructuring the classroom: Conditions for productive small groups. Review of Research in Education, 64(1), 1-35.

[6] Lave, J. \& Wenger, E. (1991). Situated Learning: Legitimate Peripheral Participation. New York: Cambridge University Press.

[7] Barron, B. (2003). When smart groups fail. Journal of the Learning Sciences, 12(3), 307-359.

[8] Barron, B. (2000). Achieving coordination in collaborative problem-solving groups. Journal of the Learning Sciences, 9(4), 403-436.

[9] Mercer, N. (1996). The quality of talk in children's collaborative activity in the classroom. Learning and Instruction, 6(4), 359-377.

[10] Dewey, J. (1913). Interest and effort in education. Boston, MA: Riverside.

[11] Hidi, S., \& Baird, W. (1986). Interestingness - A Neglected variable in discourse processing. Cognitive Science, 10, 179-194.

[12] Vygotsky, L. S. (1978). Mind and society: The development of higher mental processes. Cambridge, MA: Harvard University Press.

[13] Wertsch, J. (1993). Voices of the mind: A sociocultural approach to mediated action. Cambridge, MA: Harvard University Press.

[14] Ryu, S. \& Lombardi, D. (2015). Coding classroom interactions for collective and individual engagement. Educational Psychologist, 50(1), 70-83.

[15] Herrenkohl, L. R., \& Guerra, M. R. (1998). Participant structures, scientific discourse, and student engagement in fourth grade. Cognition and Instruction, 16, 431-473.

[16] Sullivan, F.R. (2008). Robotics and science literacy: Thinking skills, science process skills, and systems understanding. Journal of Research in Science Teaching, 45(3), 373-394.

[17] Sullivan, F.R. (2011). Serious and playful inquiry: Epistemological aspects of collaborative creativity. Journal of Educational Technology and Society, 14(1), 55-65.

[18] Toulmin, S. E. (1964). The uses of argument. Cambridge: Cambridge University Press.

[19] Erduran, S., Osborne, J., \& Simon, S. (2004). TAPping into argumentation: Developments in the application of Toulmin. Science Education, 88(6), 915-933.

[20] Sullivan, F.R., Adrion, W.R. \& Keith, P.K. (2015). Microgenetic learning analytics: A computational approach to research on student learning. Paper presentation at the annual meeting of the American Educational Research Association, Chicago, IL, April 16-20, 2015.

[21] Toutanova, K., Klein, D., Manning, C., \& Singer, Y. (2003). Feature-rich part-of-speech tagging with a cyclic dependency network. Proceedings of HLT-NAACL, (pp. 252-259).

[22] Santorini, B. (1990). Part-of-speech tagging guidelines for the Penn Treebank project ( $3^{\text {rd }}$ revision). Online Available http://repository.upenn.edu/cis_reports/570/?utm_source=rep ository.upenn.edu\%2Fcis_reports\%2F570\&utm_medium=P DF\&utm_campaign $=$ PDFCoverPages

[23] Bakhtin, M.M. (1986). The problem of speech genres. In V.W. McGee, Trans., C. Emerson \& M. Holquist (Eds.). Speech genres and other late essays (pp. 60-102). Austin, TX: University of Texas Press.

[24] Esmonde, I. (2009). Ideas and identities: Supporting equity in cooperative mathematics learning. Review of Educational Research, 79(2), 1008-1043.

[25] Anderson, D., Thomas, G.P., \& Nashon, S.M. (2009). Social barriers to meaningful engagement in biology field trip group work. Science Education, 93(3), 511-534.

[26] Strough, J.N., Berg, C.A., \& Meegan,S.P. (2001). Friendship and gender differences in task and social interpretations of peer collaborative problem solving. Social Development, 10(1), 1-22. 